\title{
The UGT1A6_19_GG genotype is a breast cancer risk factor
}

\author{
Christina Justenhoven ${ }^{1 *}$, Ofure Obazee ${ }^{1}$, Stefan Winter ${ }^{1}$, Sylvia Rabstein ${ }^{2}$, Anne Lotz ${ }^{2}$, \\ Volker Harth ${ }^{2,3}$, Beate Pesch ${ }^{2}$, Thomas Brüning ${ }^{2}$, Christian Baisch ${ }^{4}$, Jaana M. Hartikainen ${ }^{5,6}$, \\ Arto Mannermaa ${ }^{5,6}$, Veli-Matti Kosma ${ }^{5,6}$, Vesa Kataja ${ }^{7,8}$, Robert Winqvist ${ }^{9}$, Katri Pylkäs ${ }^{9}$, \\ Arja Jukkola-Vuorinen ${ }^{10}$, Mervi Grip ${ }^{11}$, Peter A. Fasching ${ }^{12,13}$, Matthias Beckmann ${ }^{12}$, Arif B. Ekici ${ }^{13}$, \\ Alexander Hein ${ }^{12}$, Per Hall ${ }^{14}$, Jingmei Li ${ }^{15}$, Jenny Chang-Claude ${ }^{16}$, Dieter Flesch-Janys ${ }^{17}$, \\ Petra Seibold ${ }^{16}$, Anja Rudolph ${ }^{16}$, Ute Hamann ${ }^{18}$, Yon-Dschun Ko ${ }^{4}$ and Hiltrud Brauch ${ }^{1}$
}

${ }^{1}$ Dr. Margarete Fischer-Bosch-Institute of Clinical Pharmacology, University of Tuebingen, Stuttgart, Germany

2 Institute for Prevention and Occupational Medicine of the German Social Accident Insurance, Bochum, Germany

${ }^{3}$ Institute for Occupational Medicine and Maritime Medicine, University Medical Center Hamburg-Eppendorf, Hamburg, Germany

${ }^{4}$ Department of Internal Medicine, Evangelische Kliniken Bonn gGmbH, Johanniter Krankenhaus, Bonn, Germany

${ }^{5}$ Cancer Center of Eastern Finland, School of Medicine, Institute of Clinical Medicine, Pathology and Forensic Medicine, University of Eastern Finland, Biocenter Kuopio, Kuopio, Finland

${ }^{6}$ Department of Pathology, Imaging Center, Kuopio University Hospital, Kuopio, Finland

Cancer Center, Kuopio University Hospital, Kuopio, Finland

${ }^{8}$ Cancer Center of Eastern Finland, School of Medicine, Institute of Clinical Medicine Oncology, University of Eastern Finland, Biocenter Kuopio, Kuopio, Finland

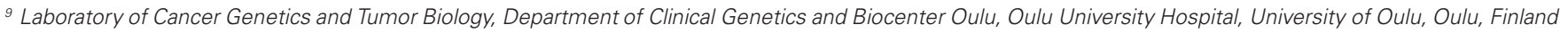

${ }^{10}$ Department of Oncology, Oulu University Hospital, University of Oulu, Oulu, Finland

$"$ Department of Surgery, Oulu University Hospital, University of Oulu, Oulu, Finland

12 Institute of Human Genetics, University Hospital Erlangen, Friedrich-Alexander University Erlangen-Nuremberg, Erlangen, Germany

${ }^{13}$ Division Hematology/Oncology, Department of Medicince, David Geffen School of Medicine, University of California at Los Angeles, Los Angeles, CA, USA

${ }^{14}$ Department of Medical Epidemiology and Biostatistics, Karolinska Institute, Stockholm, Sweden

${ }^{15}$ Human Genetics, Genome Institute of Singapore, Singapore, Singapore

${ }^{16}$ Division of Cancer Epidemiology, German Cancer Research Center (DKFZ), Heidelberg, Germany

17 Department of Medical Biometry and Epidemiology, Center for Experimental Medicine, University Medical Center Hamburg-Eppendorf, Hamburg, Germany

${ }_{18}$ Molecular Genetics of Breast Cancer, Deutsches Krebsforschungszentrum, Heidelberg, Germany

Edited by:

José A. G. Agúndez, University of Extremadura, Spain

Reviewed by:

Rosane Vianna-Jorge, Instituto Nacional de Câncer, Brazil

Wanqing Liu, Purdue University, USA

\section{*Correspondence.}

Christina Justenhoven, Bioscientia Center for Human Genetics, Konrad-Adenauer-Strasse 17, 55218 Ingelheim, Germany e-mail: christina.justenhoven@ bioscientia.de
Validation of an association between the UGT1A6_19_T>G (rs6759892) polymorphism and overall breast cancer risk. A pilot study included two population-based case-control studies from Germany (MARIE-GENICA). An independent validation study comprised four independent breast cancer case-control studies from Finland (KBCP, OBCS), Germany (BBCC), and Sweden (SASBAC). The pooled analysis included 7418 cases and 8720 controls from all six studies. Participants were of European descent. Genotyping was done by MALDI-TOF MS and statistical analysis was performed by logistic regression adjusted for age and study. The increased overall breast cancer risk for women with the UGT1A6_19_GG genotype which was observed in the pilot study was confirmed in the set of four independent study collections (OR 1.13,95\% Cl 1.05-1.22; $p=0.001$ ). The pooled study showed a similar effect (OR 1.09, 95\% Cl 1.04-1.14; $p=0.001$ ). The risk effect on the basis of allele frequencies was highly significant, the pooled analysis showed an OR of $1.11\left(95 \% \mathrm{Cl} 1.06-1.16 ; p=5.8 \times 10^{-6}\right)$. We confirmed the association of UGT1A6_19_GG with increased overall breast cancer risk and conclude that our result from a well powered multi-stage study adds a novel candidate to the panel of validated breast cancer susceptibility loci.

Keywords: UGT1A6, polymorphism, breast cancer risk, validation, metabolism

\section{INTRODUCTIONS}

Many breast cancer genes have been identified including BRCA1, BRCA2, TP53, ATM, CHEK2, BRIP1 and PALB2 which are causative for hereditary breast cancers (Narod et al., 1995; Ford et al., 1998; Easton et al., 2007). Moreover, more than 20 common genetic variants have been shown to contribute to breast cancer risk; among these, the fibroblast growth factor receptor 2 (FGFR2) polymorphism rs2981582 as well as loci close to the cell cycle regulator Cyclin D1 (CCND1) at 11q13 are the most prominent risk loci (Easton et al., 2007; Lambrechts et al., 2012). Most of these loci have been identified by genome-wide association studies
(GWAS) (Easton et al., 2007; Turnbull et al., 2010; Lambrechts et al., 2012). However, a shortcoming of this powerful approach is the lack of a sufficient coverage of polymorphisms in gene regions with high sequence similarities to other genes or pseudo genes. Genetic variations in such gene regions require an adapted primer design and amplification conditions which allow specific genotyping of the loci of interest (Justenhoven et al., 2010; The MARIE-GENICA Consortium, 2010). Therefore, polymorphic loci in homologous sequences are usually exempted from GWAS arrays, and can be analyzed in specially designed low-plex genotyping assays or small scale microarrays, e.g., the AmpliChip ${ }^{\circledR}$ 
CYP450 Test (Roche Diagnostic GmbH, Germany), the DMET ${ }^{\mathrm{TM}}$ Plus Solution (Affymetrix Inc. CA, USA) or the VeraCode ${ }^{\circledR}$ ADME Core Panel (Illumina, Inc. CA, USA) (Justenhoven, 2012). Sequence similarities are rather common among genes coding for phase I and II enzymes as well as transporters, for example P450 cytochrome 3A (CYP3A) genes with more than 70\% homology (Filipits et al., 1999; Domanski et al., 2001), the UDP glucuronosyl transferases 1 (UGT1) genes with more than 50\% homology (Gong et al., 2001) and the solute carrier organic anion transporter (SLCO) genes with more than $40 \%$ homology (Hagenbuch and Meier, 2004). It is of note, that these enzymes and transporters play an elementary role in the evolutionary-conserved detoxification system and in the homeostasis of endogenous molecules (Nebert, 1991; Goldstone et al., 2006).

In light of known effects of toxic compounds and steroid hormones on breast carcinogenesis, these enzymes and transporters are prime candidates for the investigation of their contribution to breast cancer risk (The MARIE-GENICA Consortium, 2010; Justenhoven et al., 2011). Thus, the UGTs are of particular interest because glucuronidation represents a major route of detoxification and elimination of xenobiotics including drugs and endobiotics (Bock and Kohle, 2005). UGT1A6 is the founding member of the UGT1 gene family and mediates the inactivation of phenolic compounds, e.g., 4-ethylphenol, acetaminophen or estradiol (Harding et al., 1988; Orzechowski et al., 1994; Raftogianis et al., 2000; Bock and Kohle, 2005). Two non-synonymous polymorphisms UGT1A6_19_T > G (rs6759892) and UGT1A6_541_A $>$ G (rs2070959) are located in exon 1 causing amino acid exchanges from serine to alanine at position 7 and threonine to alanine at position 181, respectively [GenBank: P19224]. The variant alleles have been associated with decreased activity of the UGT1A6 enzyme (Ciotti et al., 1997). We previously reported their possible effect on breast cancer risk in two populationbased case-control studies from Germany (The MARIE-GENICA Consortium, 2010). To validate the roles of UGT1A6 polymorphisms in breast cancer risk we conducted an independent confirmatory study and a pooled analysis with more than 7000 patients and 8000 controls, and report the association between the UGT1A6_19_GG genotype and an increased overall breast cancer risk.

\section{MATERIALS AND METHODS}

A total of 7148 breast cancer cases and 8472 controls from six independent cohorts were included in the analysis (Table 1). Study cohorts were selected on the basis of inclusion of female cases and controls from European descent, resident in the same region, unselected, invasive breast cancer cases and controls without history of breast cancer. Moreover, data on case-control status, age (age at diagnosis for cases and age at interview for controls), estrogen receptor (ER) and progesterone receptor (PR) needed to be available as well as DNA samples isolated from blood cells. Three studies were from Germany: the Bavarian Breast Cancer Cases and Controls Collection (BBCC), the Gene Environment Interactions and Breast Cancer study (GENICA), and the Mammary Carcinoma Risk Factor Investigation (MARIE). Two studies were from
Finland: the Kuopio Breast Cancer Project (KBCP) and the Oulu Breast Cancer Study (OBCS). One study was from Sweden: the Singapore and Sweden Breast Cancer Study (SASBAC). All studies were approved by respective ethic committees and all participants gave written informed consent. Each individual study provided data on case-control status, age, ER and PR status as well as ethnicity. All study participants were of European descent.

Blood-derived DNA samples of all cases and controls were genotyped for UGT1A6_19_T > G and UGT1A6_541_A $>$ G by matrix-assisted laser desorption/ionization mass spectrometry (MALDI-TOF MS; Sequenom, San Diego, CA) as described previously (The MARIE-GENICA Consortium, 2010). Genetic analyses included negative controls and $10 \%$ randomly selected duplicate samples for quality control. Call rates were greater than $98 \%$ and repeated analyses of the duplicate samples showed 100\% concordance. UGT1A6_19_T > G and UGT1A6_541_A > G genotype frequencies met the Hardy-Weinberg equilibrium.

Associations between UGT1A6_19_T $>$ G and UGT1 A6_541_A $>$ G genotypes and breast cancer risk were analyzed by logistic regression adjusted for age and study using SPSS software v 15.0 (SPSS Inc., IBM Corporation, Somers, NY). Four subgroup analyses were performed including the analysis of ER-positive cases vs. controls, ER-negative cases vs. controls, PR-positive cases versus controls, and PR-negative cases vs. controls. Risk estimates were calculated as odds ratios (OR) with 95\% confidence interval (95\% CI) and corresponding $p$-value. Power calculation was done by nQuery Advisor ${ }^{\circledR}$ 4.0.

\section{RESULTS}

Our validation study had $80 \%$ power to detect a minimum OR of 1.06 and 1.07 for the UGT1A6_19_T $>G$ and UGT1A6_541_A $>$ G polymorphisms, respectively $(\alpha=0.05$, two-sided test). We observed no breast cancer risk association for the UGT1A6_541_A > G genotypes and none of the two variants showed an association with tumor ER and PR status (data not shown).

For the UGT1A6_19_T >G polymorphism, we confirmed an increased breast cancer risk for women carrying the homozygous variant GG genotype (Table 2). This finding complements our two-stage study in which carriers of the UGT1A6_19_GG genotype showed an OR of 1.17 (95\% CI 1.03-1.34; $p=0.014$ ) in the previous pilot investigation (stage 1) (The MARIEGENICA Consortium, 2010). This result was based on adjustment for duration of any hormone replacement therapy, type of menopause, number of births, ever having breastfed, ever having smoked, number of mammograms, ever having had benign breast disease, family history of breast cancer in 1st degree relatives, body mass index, study region, and year of birth in 5 year categories. Adjustment for age and study only showed a similar risk effect with an OR of 1.09 (95\% CI 1.02-1.16; $p=0.009$ ) for the UGT1A6_19_GG genotype (Table 2). The confirmation of the increased overall breast cancer risk of OR 1.13 (95\% CI 1.05-1.22; $p=0.001$; Table 2) is reported herein (stage 2 using four independent cohorts BBCC, KBCP, OBCS, and SASBAC). The pooled analysis of BBCC, KBCP, OBCS, SASBAC, GENICA, and MARIE again confirmed the UGT1A6_19_GG genotype as a breast cancer 
Table 1 | Description of study design for each participating study.

\begin{tabular}{|c|c|c|c|c|}
\hline Study (References) & Country & Case definition and ascertainment & $\begin{array}{l}\text { Control definition and } \\
\text { ascertainment }\end{array}$ & $\begin{array}{l}\text { Age range of } \\
\text { cases/controls }\end{array}$ \\
\hline $\begin{array}{l}\text { BBCC: } \\
\text { Bavarian Breast Cancer Cases and } \\
\text { Controls (Fasching et al., 2008; } \\
\text { Schrauder et al., 2008) }\end{array}$ & Germany & $\begin{array}{l}\text { Consecutive, unselected cases with } \\
\text { invasive breast cancer recruited at the } \\
\text { University Breast Centre, Franconia in } \\
\text { Northern Bavaria during 2002-2006. }\end{array}$ & $\begin{array}{l}\text { Healthy women with no diagnosis of } \\
\text { cancer aged } 55 \text { or older. Invited by a } \\
\text { newspaper advertisement in } \\
\text { Northern Bavaria, and recruited } \\
\text { during 2002-2006. }\end{array}$ & $22-96 / 18-100$ \\
\hline $\begin{array}{l}\text { GENICA: } \\
\text { Gene Environment Interaction and } \\
\text { Breast Cancer in Germany (Pesch } \\
\text { et al., 2005; Justenhoven et al., 2008) }\end{array}$ & Germany & $\begin{array}{l}\text { Incident breast cancer cases were } \\
\text { enrolled from } 2000 \text { to } 2004 \text { from the } \\
\text { Greater Bonn area (from all hospitals } \\
\text { within the study region); cases were } \\
\text { enrolled within } 6 \text { months of } \\
\text { diagnosis. }\end{array}$ & $\begin{array}{l}\text { Controls were selected from } \\
\text { population registries from } 31 \\
\text { communities in the greater Bonn } \\
\text { area; matched to cases in } 5 \text {-year age } \\
\text { classes from } 2001 \text { to } 2004 \text {. }\end{array}$ & $23-80 / 24-80$ \\
\hline $\begin{array}{l}\text { MARIE: } \\
\text { Mammary Carcinoma Risk Factor } \\
\text { Investigation (Flesch-Janys et al., } \\
\text { 2008) }\end{array}$ & Germany & $\begin{array}{l}\text { Incident and prevalent cases } \\
\text { diagnosed from } 2001 \text { to } 2005 \text { in the } \\
\text { study region Hamburg in Northern } \\
\text { Germany, and from } 2002 \text { to } 2005 \text { in } \\
\text { the study region } \\
\text { Rhein-Neckar-Karlsruhe in Southern } \\
\text { Germany. }\end{array}$ & $\begin{array}{l}\text { Two controls per case were randomly } \\
\text { drawn from population registries and } \\
\text { frequency matched by birth year and } \\
\text { study region to the case. Controls } \\
\text { were recruited from } 2002 \text { to } 2006 \text {. }\end{array}$ & $50-75 / 49-75$ \\
\hline $\begin{array}{l}\text { KBCP: } \\
\text { Kuopio Breast Cancer Project } \\
\text { (Hartikainen et al., 2005, 2006) }\end{array}$ & Finland & $\begin{array}{l}\text { Women seen at Kuopio University } \\
\text { Hospital between } 1990 \text { and } 1995 \\
\text { because of breast lump, } \\
\text { mammographic abnormality, or other } \\
\text { breast symptom who were found to } \\
\text { have breast cancer. }\end{array}$ & $\begin{array}{l}\text { Age and long-term area-of-residence } \\
\text { matched controls selected from the } \\
\text { National Population Register and } \\
\text { interviewed in parallel with the cases. }\end{array}$ & $23-92 / 27-77$ \\
\hline $\begin{array}{l}\text { OBCS: } \\
\text { Oulu Breast Cancer Study (Wedren } \\
\text { et al., 2004; Erkko et al., 2007) }\end{array}$ & Finland & $\begin{array}{l}\text { Consecutive incident cases } \\
\text { diagnosed at the Oulu University } \\
\text { Hospital between } 2000 \text { and } 2004 \text {. }\end{array}$ & $\begin{array}{l}\text { Healthy, consecutive, anonymous, } \\
\text { female Finnish Red-Cross blood } \\
\text { donors recruited in } 2002 \text { from the } \\
\text { same geographical region in Northern } \\
\text { Finland. }\end{array}$ & 28-92/18-66 \\
\hline $\begin{array}{l}\text { SASBAC: } \\
\text { Singapore and Sweden Breast } \\
\text { Cancer Study (Wedren et al., 2004) }\end{array}$ & Sweden & $\begin{array}{l}\text { Incident cases from } 1993 \text { to } 1995 \\
\text { identified via the } 6 \text { regional cancer } \\
\text { registries in Sweden, to which } \\
\text { reporting is mandatory. }\end{array}$ & $\begin{array}{l}\text { Controls were randomly selected } \\
\text { from the total population registry in } \\
\text { 5-year age groups to match the } \\
\text { expected age-frequency distribution } \\
\text { among cases. Patients and controls } \\
\text { were recruited from } 1993 \text { to } 1995 .\end{array}$ & $50-75 / 49-76$ \\
\hline
\end{tabular}

risk factor with an OR of 1.09 (95\% CI 1.04-1.14; $p=0.001$; Table 2).

In addition to the genotype frequencies the risk effect of the UGT1A6_19_G allele was analyzed on the level of allele frequencies and showed ORs of 1.08 (95\% CI 1.01-1.15: $p=0.012), 1.10$ (95\% CI 1.02-1.18; $p=0.12$ ), and 1.11 (95\% CI 1.06-1.16; $p=$ $5.86 \times 10^{-6}$ ) in the pilot and validation study as well as pooled analysis, respectively.

\section{DISCUSSION}

We confirmed the UGT1A6_19_GG genotype as an overall breast cancer risk factor, first, in an independent validation study including breast cancer cases and controls from Finland, Germany and Sweden as well as in a pooled analysis of more than 15,000 study subjects following our initial report from a German pilot study
(The MARIE-GENICA Consortium, 2010). This finding supports the notion that reduced activity of detoxification enzymes such as UGT1A6 contribute to an overall breast cancer risk. The present study highlights the necessity to extend investigations for the discovery of breast cancer susceptibility loci to enzymes involved in detoxification processes despite their inherent problem of high homology which excludes them from standard GWAS approaches. As of yet, although GWAS approaches have delivered more than 20 common breast cancer risk loci (Turnbull et al., 2010; Ghoussaini et al., 2012), there is a possibility, that tailored approaches to cover variants in regions of sequence homology may add to the growing list of genetic risk factors.

It is of note that the herein observed ORs for the UGT1A6_19_G variant are in the range of the so far established 
Table 2 | Association of UGT1A6_19_T> G with breast cancer risk.

\begin{tabular}{|c|c|c|c|c|c|}
\hline Study & $\begin{array}{l}\text { UGT1A6_19_T>G } \\
\text { genotypes and alleles }\end{array}$ & Cases $(\%)$ & Controls (\%) & OR $(95 \% \mathrm{Cl})$ & $p$-value \\
\hline \multicolumn{6}{|l|}{ PILOT STUDY } \\
\hline \multirow[t]{7}{*}{ (The MARIE-GENICA Consortium, 2010) } & $\mathrm{TG}$ & $1544(49.2)$ & $2644(48.4)$ & $1.10^{\mathrm{b}}(0.99-1.21)$ & \\
\hline & GG & $589(18.7)$ & $940(17.2)$ & $1.17^{b}(1.03-1.34)$ & $0.014^{c}$ \\
\hline & $\mathrm{TT}$ & 1134 (32.3) & 2017 (34.6) & $1.00^{\mathrm{a}}$ & \\
\hline & GG & $654(18.6)$ & $1000(17.2)$ & $1.09(1.02-1.16)$ & 0.009 \\
\hline & $\mathrm{TG}+\mathrm{GG}$ & 2379 & 3807 & $1.12(1.02-1.23)$ & 0.013 \\
\hline & $\mathrm{T}$ & $3556(56.6)$ & $6408(58.6)$ & $1.00^{\mathrm{a}}$ & \\
\hline & G & $2722(43.4)$ & $4524(41.4)$ & $1.08(1.01-1.15)$ & 0.012 \\
\hline \multicolumn{6}{|l|}{ VALIDATION STUDY } \\
\hline \multirow{2}{*}{ BBCC, KBCP, OBCS, SASBAC } & $\mathrm{T}$ & $3933(54.1)$ & $2987(62.5)$ & $1.00^{\mathrm{a}}$ & \\
\hline & G & $3337(45.9)$ & $1790(37.5)$ & $1.10(1.02-1.18)$ & 0.012 \\
\hline \multicolumn{6}{|l|}{ POOLED ANALYSIS } \\
\hline MARIE-GENICA, BBCC, KBCP, & $\mathrm{TT}$ & $2279(31.9)$ & 2875 (33.9) & $1.00^{\mathrm{a}}$ & \\
\hline \multirow[t]{5}{*}{ OBCS, SASBAC } & $\mathrm{TG}$ & $3368(47.1)$ & $4076(48.1)$ & $1.03^{d}(0.96-1.11)$ & 0.418 \\
\hline & GG & $1501(21.0)$ & $1521(18.0)$ & $1.09^{d}(1.04-1.14)$ & 0.001 \\
\hline & $\mathrm{TG}+\mathrm{GG}$ & 4869 & 5597 & $1.07^{d}(1.00-1.15)$ & 0.041 \\
\hline & $\mathrm{T}$ & $7926(55.4)$ & $9826(58.0)$ & $1.00^{\mathrm{a}}$ & \\
\hline & G & $6370(44.6)$ & $7118(42.0)$ & $1.11(1.06-1.16)$ & $5.86 \times 10^{-6}$ \\
\hline
\end{tabular}

Cl, confidence interval; OR, odds ratio.

${ }^{a}$ Reference.

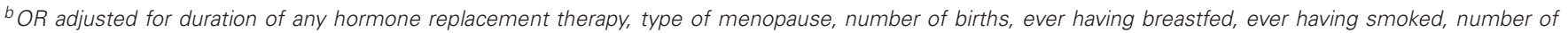

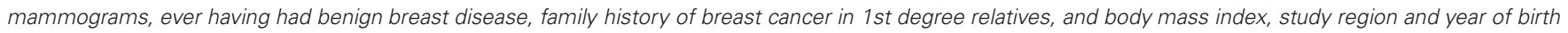
in 5 year categories.

${ }^{c} p$-value from a log additive model as published.

${ }^{d} \mathrm{OR}$ adjusted for age and study.

common low-penetrance breast cancer susceptibility loci with ORs from 1.07 to 1.22 including polymorphisms in genes such as FGFR2 and TOX3. As of yet, this set of more than 20 known susceptibility loci accounts for about $8 \%$ of the heritability of breast cancer (Ghoussaini et al., 2012). Therefore, it will be of particular interest to evaluate the UGT1A6 polymorphism in concert with all known risk factors in large study collections to establish a more comprehensive breast cancer susceptibility panel.

We analyzed a potential association of the UGT1A6_19_T > G polymorphism with ER and PR status of breast tumors and observed no effect. Other histopathological variables were not included in the analyses herein due to missing data and variables as well as differences in the collection and documentation of these variables among studies. Since breast cancer is a heterogeneous disease it will be of interest to analyze the association of this polymorphism and breast cancer subtypes in large study collections with a broad set of hisopathological variables.

The role of a UGT1A6 variant for breast cancer risk is reasonable because a reduction of enzyme activity has been previously suggested (Ciotti et al., 1997). Moreover, it is well known that UGT1A6 is involved in the conjugation of steroid hormones (Raftogianis et al., 2000) and increased levels of sex hormones are a known risk factor for breast cancer (Key et al., 2002). UGT1A6 also conjugates exogenous compounds which occur in the environment and in food, e.g., 4-ethylphenol or in drugs, e.g., acetaminophen (Harding et al., 1988; Bock and Kohle, 2005), which together with other UGT1A6 substrates have been suggested to affect breast cancer risk (Friis et al., 2008; Chen et al., 2011).

\section{CONCLUSION AND PERSPECTIVES}

The present study which is limited to women of European descent holds the potential for further validation of the UGT1A6 and other functionally related enzymes in a more in-depth global context. Currently, we consider the prediction of breast cancer risk by polymorphisms of phase I and II enzymes in its initial stage and encourage further comprehensive studies to establish their contributory role in breast cancer risk. This should be done across populations and ethnicities as is potentially accessible through 
the Breast Cancer Association Consortium (BCAC) (Easton et al., 2007; Lambrechts et al., 2012). Notably, our finding expands the scope of known crucial pathways involved in breast cancer susceptibility from growth and cell cycle control to metabolic enzymes and confirms the link between the phase II enzyme UGT1A6 and breast cancer risk.

\section{ACKNOWLEDGMENTS}

We are indebted to all women who participated in this study. The GENICA was supported by the Federal Ministry of Education and Research (BMBF) Germany grants 01KW9975/5, 01KW9976/8, 01KW9977/0, 01KW0114, and 012P0502, the Robert Bosch Foundation, Stuttgart, Deutsches Krebsforschungszentrum, Heidelberg, Institute for Prevention and Occupational Medicine of the German Social Accident Insurance (IPA), Bochum Department of Internal Medicine, Evangelische Kliniken Bonn gGmbH, Johanniter Krankenhaus, Bonn, Germany. Part of the

\section{REFERENCES}

Bock, K. W., and Kohle, C. (2005). UDP-glucuronosyltransferase 1A6: structural, functional, and regulatory aspects. Methods Enzymol. 400, 57-75. doi: 10.1016/S00766879(05)00004-2

Chen, W. Y., Rosner, B., Hankinson, S. E., Colditz, G. A., and Willett, W. C. (2011). Moderate alcohol consumption during adult life, drinking patterns, and breast cancer risk. JAMA 306, 1884-1890. doi: 10.1001/jama.2011.1590

Ciotti, M., Marrone, A., Potter, C., and Owens, I. S. (1997). Genetic polymorphism in the human UGT1A6 (planar phenol) UDP-glucuronosyl transferase: pharmacological implications. Pharmacogenetics 7, 485-495.

Domanski, T. L., Finta, C., Halpert, J. R., and Zaphiropoulos, P. G. (2001). cDNA cloning and initial characterization of CYP3A43, a novel human cytochrome P450. Mol. Pharmacol. 59, 386-392.

Easton, D. F., Pooley, K. A., Dunning, A. M., Pharoah, P. D., Thompson, D., Ballinger, D. G., et al. (2007). Genome-wide association study identifies novel breast cancer susceptibility loci. Nature 447, 1087-1093. doi: $10.1038 /$ nature 05887

Erkko, H., Xia, B., Nikkila, J., Schleutker, J., Syrjakoski, K., Mannermaa, A., et al. (2007). A recurrent mutation in PALB2 in Finnish cancer families. Nature 446, 316-319. doi: 10.1038/nature05609

Fasching, P. A., Loehberg, C. R., Strissel, P. L., Lux, M. P., Bani, M. R., Schrauder, M., et al. (2008). Single nucleotide polymorphisms of the aromatase gene (CYP19A1),
HER2/neu status, and prognosis in breast cancer patients. Breast Cancer Res. Treat. 112, 89-98. doi: 10.1007/s10549-007-9822-2

Filipits, M., Malayeri, R., Suchomel, R. W., Pohl, G., Stranzl, T., Dekan, G., et al. (1999). Expression of the multidrug resistance protein (MRP1) in breast cancer. Anticancer Res. 19, 5043-5049.

Flesch-Janys, D., Slanger, T., Mutschelknauss, E., Kropp, S., Obi, N., Vettorazzi, E., et al. (2008). Risk of different histological types of postmenopausal breast cancer by type and regimen of menopausal hormone therapy. Int. J. Cancer 123, 933-941. doi: 10.1002/ijc.23655

Ford, D., Easton, D. F., Stratton, M., P., et al. (1998). Genetic heterogeneity and penetrance analysis of the BRCA1 and BRCA2 genes in breast cancer families. The Breast Cancer Linkage Consortium. Am. J. Hum. Genet. 62, 676-689. doi: 10.1086/301749

Friis, S., Thomassen, L., Sorensen, H. A. T., Tjonneland, A., Overvad, K., Cronin-Fenton, D. P., et al. (2008). drug use and breast cancer risk: a Danish cohort study. Eur. J. Cancer Prev. 17, 88-96. doi: 10.1097/CEJ.0b013e3282b6fd55

Ghoussaini, M., Fletcher, O., Michailidou, K., Turnbull, C., Schmidt, M. K., Dicks, E., et al. (2012). Genome-wide association analysis identifies three new breast cancer susceptibility loci. Nat. Genet. 44, 312-318. doi: 10.1038/ng.1049

Goldstone, J. V., Hamdoun, A., Cole, B. J., Howard-Ashby, M., Nebert, D. W., Scally, M., et al. (2006). Narod, S., Goldgar, D., Devilee, Nonsteroidal anti-inflammatory

work was funded by the 7FP EU Marie Curie Initial Training Network "FightingDrugFailure" (GA 238132). The MARIE study was supported be the Deutsche Krebshilfe e.V. [702892-BR I], the Hamburg Cancer Society, the German Cancer Research Center and genotype work by the Federal Ministry of Education and Research (BMBF) Germany [01KH0402]. SASBAC was supported by National Institutes of Health (RO1 CA58427) and Märit and Hans Rausing's Initiative Against Breast Cancer. The BBCC study was supported by the ELAN program of the University Hospital Erlangen. KBCP was supported by grants from Special Government Funding (EVO) of Kuopio University Hospital, Kuopio Northern Savo Cancer Society, Finnish Cancer Organization, the strategic funding of the University of Eastern Finland and Academy of Finland. The OBCS was supported by the University of Oulu, the Oulu University Hospital, the Finnish Cancer Society, and the Academy of Finland.

The chemical defensome: environmental sensing and response genes in the Strongylocentrotus purpuratus genome. Dev. Biol. 300, 366-384. doi: 10.1016/j.ydbio.2006. 08.066

Gong, Q. H., Cho, J. W., Huang, T., Potter, C., Gholami, N., Basu, N. K., et al. (2001). Thirteen UDP glucuronosyltransferase genes are encoded at the human UGT1 gene complex locus. Pharmacogenetics 11, 357-368.

Hagenbuch, B., and Meier, P. J. (2004). Organic anion transporting polypeptides of the OATP/ SLC21 family: phylogenetic classification as OATP/ SLCO superfamily, new nomenclature and molecular/functional properties. Pflugers Arch. 447, 653-665. doi: 10.1007/s00424-003-1168-y

Harding, D., Fournel-Gigleux, S., Jackson, M. R., and Burchell, B. (1988). Cloning and substrate specificity of a human phenol UDPglucuronosyltransferase expressed in COS-7 cells. Proc. Natl. Acad. Sci. U.S.A. 85, 8381-8385.

Hartikainen, J. M., Tuhkanen, H. Kataja, V., Dunning, A. M., Antoniou, A., Smith, P., et al. (2005). An autosome-wide scan for linkage disequilibrium-based association in sporadic breast cancer cases in eastern Finland: three candidate regions found. Cancer Epidemiol. Biomarkers Prev. 14, 75-80.

Hartikainen, J. M., Tuhkanen, H., Kataja, V., Eskelinen, M., Uusitupa, M., Kosma, V. M., et al. (2006). Refinement of the 22q12-q13 breast cancer-associated region: evidence of TMPRSS6 as a candidate gene in an eastern Finnish population. Clin.
Cancer Res. 12, 1454-1462. doi: 10.1158/1078-0432.CCR-05-1417

Justenhoven, C. (2012). Polymorphisms of phase I and phase II enzymes and breast cancer risk. Front. Gene. 3:258-262. doi: 10.3389/fgene.2012.00258

Justenhoven, C., Pierl, C. B., Haas, S., Fischer, H. P., Baisch, C., Hamann, U., et al. (2008). The CYP1B1_1358_GG genotype is associated with estrogen receptornegative breast cancer. Breast Cancer Res. Treat. 111, 171-177. doi: 10.1007/s10549-007-9762-x

Justenhoven, C., Schaeffeler, E., Winter, S., Baisch, C., Hamann, U., Harth, V., et al. (2011). Polymorphisms of the nuclear receptor pregnane $\mathrm{X}$ receptor and organic anion transporter polypeptides 1A2, 1B1, $1 \mathrm{~B} 3$, and $2 \mathrm{~B} 1$ are not associated with breast cancer risk. Breast Cancer Res. Treat. 125, 563-569. doi: 10.1007/s10549-010-1046-1

Justenhoven, C., Winter, S., Hamann, U., Haas, S., Fischer, H. P., Pesch, B., et al. (2010). The frameshift polymorphism CYP3A43_74_delA is associated with poor differentiation of breast tumors. Cancer 116, 5358-5364. doi: 10.1002/cncr.25508

Key, T., Appleby, P., Barnes, I., and Reeves, G. (2002). Endogenous hormones and breast cancer collaborative group. Endogenous sex hormones and breast cancer in postmenopausal women: reanalysis of nine prospective studies. J. Natl. Cancer Inst. 94, 606-616. doi: 10.1093/jnci/94.8.606

Lambrechts, D., Truong, T., Justenhoven, C., Humphreys, M. K., Wang, J., Hopper, J. L., et al. (2012). $11 \mathrm{q} 13$ is a susceptibility locus for hormone receptor positive breast 
cancer. Hum. Mutat. 33, 1123-1132. doi: 10.1002/humu.22089

Narod, S., Ford, D., Devilee, P., Barkardottir, R. B., Eyfjord, J., Lenoir, G., et al. (1995). Genetic heterogeneity of breast-ovarian cancer revisited. Breast Cancer Linkage Consortium. Am. J. Hum. Genet. 57, 957-958.

Nebert, D. W. (1991). Proposed role of drug-metabolizing enzymes: regulation of steady state levels of the ligands that effect growth, homeostasis, differentiation, and neuroendocrine functions. $\mathrm{Mol}$. Endocrinol. 5, 1203-1214.

Orzechowski, A., Schrenk, D., BockHennig, B. S., and Bock, K. W. (1994). Glucuronidation of carcinogenic arylamines and their N-hydroxy derivatives by rat and human phenol UDP-glucuronosyl transferase of the UGT1 gene complex. Carcinogenesis 15, 1549-1553. doi: 10.1093/carcin/15.8.1549

Pesch, B., Ko, Y., Brauch, H., Hamann, U., Harth, V., Rabstein, S., et al. (2005). Factors modifying the association between hormone-replacement therapy and breast cancer risk. Eur. J. Epidemiol. 20, 699-711. doi: 10.1007/s10654-005-0032-0

Raftogianis, R., Creveling, C., Weinshilboum, R., and Weisz, J. (2000). Estrogen metabolism by conjugation. J. Natl. Cancer Inst. Monogr. 27, 113-124.

Schrauder, M., Frank, S., Strissel, P. L., Lux, M. P., Bani, M. R., Rauh, C., et al. (2008). Single nucleotide polymorphism D1853N of the ATM gene may alter the risk for breast cancer. J. Cancer Res. Clin. Oncol. 134, 873-882. doi: 10.1007/s00432-0080355-9

The MARIE-GENICA Consortium on Genetic Susceptibility for Menopausal Hormone Therapy Related Breast Cancer Risk. (2010). Genetic polymorphisms in phase I and phase II enzymes and breast cancer risk associated with menopausal hormone therapy in postmenopausal women. Breast Cancer Res. Treat. 119, 463-474. doi: 10.1007/s10549-0090407-0
Turnbull, C., Ahmed, S., Morrison, J., Pernet, D., Renwick, A., Maranian, M., et al. (2010). Genome-wide association study identifies five new breast cancer susceptibility loci. Nat. Genet 42, 504-507. doi: 10.1038/ng.586

Wedren, S., Lovmar, L., Humphreys, K., Magnusson, C., Melhus, H., Syvanen, A. C., et al. (2004). Oestrogen receptor alpha gene haplotype and postmenopausal breast cancer risk: a case control study. Breast Cancer Res. 6, R437-R449. doi: $10.1186 /$ bcr811

Conflict of Interest Statement: The authors declare that the research was conducted in the absence of any commercial or financial relationships that could be construed as a potential conflict of interest.

Received: 11 April 2013; accepted: 22 May 2013; published online: 11 June 2013

Citation: Justenhoven C, Obazee O, Winter S, Rabstein S, Lotz A, Harth $V$, Pesch B, Brüning T, Baisch C, Hartikainen JM, Mannermaa A, Kosma
$V$-M, Kataja V, Winqvist $R$, Pylkäs $K$, Jukkola-Vuorinen A, Grip M, Fasching PA, Beckmann $M$, Ekici AB, Hein A, Hall P, Li J, Chang-Claude J, FleschJanys D, Seibold P, Rudolph A, Hamann U, Ko Y-D and Brauch $H$ (2013) The UGT1A6_19_GG genotype is a breast cancer risk factor. Front. Genet. 4:104. doi: 10.3389/fgene.2013.00104

This article was submitted to Frontiers in Pharmacogenetics and Pharmacogenomics, a specialty of Frontiers in Genetics.

Copyright (C) 2013 Justenhoven, Obazee, Winter, Rabstein, Lotz, Harth, Pesch, Brüning, Baisch, Hartikainen, Mannermaa, Kosma, Kataja, Winqvist, Pylkäs, Jukkola-Vuorinen, Grip, Fasching, Beckmann, Ekici, Hein, Hall, Li, Chang-Claude, Flesch-Janys, Seibold, Rudolph, Hamann, Ko and Brauch. This is an open-access article distributed under the terms of the Creative Commons Attribution License, which permits use, distribution and reproduction in other forums, provided the original authors and source are credited and subject to any copyright notices concerning any third-party graphics etc. 